\title{
PRODUÇÃO DE MUDAS DE BARU (Dipteryx alata Vog.) SOB TRÊS NÍVEIS DE SOMBREAMENTO E QUATRO CLASSES TEXTURAIS DE SOLO ${ }^{1}$
}

\author{
ANA CRISTINA ARAÚJO AJALLA², EDIMILSON VOLPE \\ MARIA DO CARMO VIEIRA ${ }^{4}$, NÉSTOR ANTONIO HEREDIA ZÁRATE ${ }^{4}$
}

RESUMO - Foi avaliado o desenvolvimento de mudas de baru (Dipteryx alata Vog.) em vasos, sob três níveis de sombreamento e quatro classes texturais do solo, no período de março a outubro de 2010, em Campo Grande-MS. Os tratamentos consistiram em 0\%, 30\% e 50\% de sombreamento e solos de textura arenosa, média, argilosa e muito argilosa. O delineamento experimental foi em blocos ao acaso, em parcelas subdivididas, com medidas repetidas no tempo. Foram utilizadas três repetições e dez plantas por subparcela. Os níveis de sombreamento corresponderam aos tratamentos, e as diferentes classes texturais do solo, aos subtratamentos. As plantas foram avaliadas em intervalos de 15 dias após a emergência (DAE) até 195 DAE, sendo avaliadas quanto à altura (cm) de plantas, número de folhas e diâmetro do coleto (mm). Aos 195 DAE, também foram avaliadas a percentagem de sobrevivência, a área foliar e a massa seca de folha, caule e das raízes das plantas. Sob sombreamento, foram observados maiores valores de altura e área foliar. A altura de plantas foi de 32,09 cm e 31,21 cm planta-1 , e a área foliar foi de 639,24 cm² e 580,49 cm² planta $^{-1}$ para $^{2}$ os níveis de sombreamento de $50 \%$ e $30 \%$, respectivamente. No solo de textura argilosa, os valores foram superiores na maioria das características avaliadas, seguido do solo com textura muito argilosa. A maior

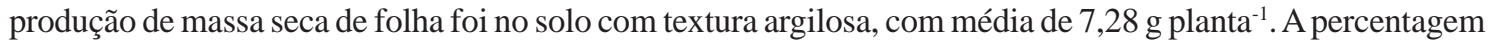
de sobrevivência das mudas no solo com textura arenosa foi inferior aos demais. Houve interação entre níveis de sombreamento e classes texturais do solo na massa seca de raízes, que foi maior (1,43 g kg-1 de solo) no solo de textura muito argilosa, no nível de 50\% de sombreamento. As mudas de baru atingiram medidas de altura e diâmetro de coleto adequadas em todos os níveis de sombreamento e classes texturais do solo.

Termos para indexação: planta nativa, Cerrado, substrato.

\section{PRODUCTION OF BARU (DipteryxalataVog.) SEEDLINGS UNDER THREE LEVELS OF SHADING AND FOUR TEXTURAL CLASSES OF SOIL}

\begin{abstract}
It was evaluated the development of “Baru” seedlings (DipteryxalataVog.) in pots under three levels of shading and four textural classes, from March to October 2010, in Campo Grande-MS. Treatments consisted of $0 \%, 30 \%$ and $50 \%$ levels of shade and sandy, medium clay and heavy clay soil. The experimental design was randomized blocks in split plots with repeated measures. It was used three replicates of ten plants per plot. The shading levels corresponded to the treatments and the different textural classes to the subplot. Plant height, leaf number and stem diameter were evaluated 15 days after emergence (DAE) to 195 DAE. Survival rate, leaf area and dry mass of the leaf, the stem and the roots were also estimated at 195 DAE. Higher values were observed in height and leaf area under shading condition. Plant height was $32.09 \mathrm{~cm}$ and $31.21 \mathrm{~cm}$ plant ${ }^{-1}$, leaf area was $639.24 \mathrm{~cm}^{2}$ and $580.49 \mathrm{~cm}^{2}$ for $50 \%$ and $30 \%$ shade levels respectively. In clay soil the values were higher in most traits followed by soil with loamy soil. The highest yield of dry mass of leaf was in the clayey soil with an average of $7.28 \mathrm{~g} \mathrm{plant}^{-1}$.The percentage of seedling survival in sandy soil was lower than in the others. There was an interaction between levels of shading and texture classes of soil on dry mass of the roots which was higher $\left(1.43 \mathrm{~g} \mathrm{~kg}^{-1}\right.$ soil) on the loamy soil at $50 \%$ shading. "Baru" seedlings reached measurements of height and diameter suitable for all levels of shading and textural classes.
\end{abstract}

Index terms: native plant, Savannah, substrate.

${ }^{1}$ (Trabalho 006-12). Recebido em: 02-01-2012. Aceito para publicação em: 25-07-2012.

${ }^{2}$ Doutoranda em Agronomia - UFGD/ AGRAER; bolsista FUNDECT. Rodovia MS 080 Km 10, CEP 79.114-000-Campo GrandeMS.E-mails: anajallaagraer@gmail.com; acaa337@hotmail.com .

${ }^{3} \mathrm{Dr}^{0}$ Pesquisador AGRAER. Rodovia MS 080 Km 10, CEP 79.114-000-Campo Grande-MS. E-mail: edvolpeagraer@gmail.com. ${ }^{4}$ Professores UFGD, Bolsistas de Produtividade em Pesquisa CNPq. Rodovia Dourados Itahum Km 12, CP 533, CEP: 79804-970, Dourados - MS. E-mail: mariavieira@terra.com.br 


\section{INTRODUÇÃO}

O baru (Dipteryx alata Vog., Fabaceae) é uma planta arbórea que ocorre principalmente em áreas cujos solos apresentam média fertilidade, sendo viável sua utilização para diversos fins, tais como: sombreamento; forragem; madeira; alimentação humana, e reciclagem de nutrientes, pela decomposição da serrapilheira, sendo considerada uma frutífera do Cerrado promissora para cultivo com fins comerciais (SANO et al, 2006). Contudo, sua exploração é efetuada por meio de extrativismo e são escassas as informações sobre biologia e manejo que permitam sua utilização sustentável.

Os frutos contêm amêndoas com alto valor proteico, superior ao do amendoim (SOUSA et al., 2011), bem como altos teores de lipídios, ferro e zinco (FERNANDES et al., 2010).

$\mathrm{O}$ amadurecimento dos frutos geralmente ocorre de julho a outubro, dependendo do local e do ano. Em Mato Grosso do Sul, verificaram-se picos de frutificação de março a julho em 2005 e maio a agosto em 2006 (OLIVEIRA;SIGRIST, 2008), sendo variável entre anos e plantas.

Em revisão, Zaidan e Carreira (2008) relatam a necessidade de a semente de baru permanecer por um período dentro do fruto para alcançar índice de germinação elevado. Sano e Fonseca (2003) verificaram altas taxas de sobrevivência de mudas, o que é um aspecto facilitador para seu cultivo. A definição de um sistema de cultivo para o baru, no entanto, ainda é uma tarefa não realizada; nesse sentido, a tecnologia de produção de mudas é um item fundamental.

Considera-se que uma muda de espécie arbórea de boa qualidade deva apresentar altura variando entre 20-35 cm, diâmetro de coleto entre 5-10 mm, além de bom estado nutricional, fitossanitário e boas condições de raízes (PACHECO, 2008). O índice de qualidade de Dickson é também um parâmetro considerando como um bom indicador de qualidade de muda (COELHO et al., 2008; COSTA al., 2011), sendo um índice adotado em vários estudos relativos à sua produção (MARANA, et al., 2008; MELO et al, 2008; BINOTTO et al., 2010; GODOY; ROSADO, 2011). Tendo em vista a época de maturação dos frutos de baru e a necessidade de um período de pós-maturação das sementes, deve-se considerar que a muda desta espécie poderá atingir seu ponto ideal de plantio somente no final do verão/início do outono do ano seguinte à colheita dos frutos, o que pode ser um fator limitante ao estabelecimento da planta no campo, face às condições de umidade e temperatura prevalecentes neste período. Assim, é importante verificar a viabilidade da produção de mudas de baru de forma a estarem prontas para plantio a partir da primavera, início da estação das chuvas, bem como sua realização nas condições da propriedade rural.

Na produção de mudas, o substrato a ser utilizado é um fator importante. Para a maioria das espécies do Cerrado, recomenda-se a utilização de solo de textura média. Em condições de pleno sol, Rosa et al. (2006), estudando o desenvolvimento de mudas de baru sob seis diferentes substratos, concluíram que a composição do substrato interferiu no comprimento da parte aérea, na massa seca da parte aérea e da raiz. No substrato composto por solo de Cerrado, os autores verificaram maior altura de plantas (20,40 cm) e massa seca de raiz (1,93 g), e no substrato composto de solo de Cerrado + composto orgânico (1:1), maior valor de massa seca da parte aérea (2,44 g), quando comparados com substratos com areia + composto (1:1), solo de Cerrado + areia, (1:1:1) e solo do Cerrado + areia + composto (1:1:1), ou seja, em substratos com areia o desenvolvimento foi menor. Pacheco (2008), em solo com 50\% de argila, estudou doses de adubação química associada com $0 \%, 10 \%$ e $20 \%$ de esterco de curral na produção de mudas de baru. $\mathrm{O}$ autor concluiu que todos os tratamentos testados permitiram a produção de mudas de boa qualidade, exceto a testemunha sem nenhuma adubação, e o tratamento com $10 \%$ de esterco sem adubação química. Paiva Sobrinho et al. (2010) avaliaram o desenvolvimento de mudas de baru em diferentes substratos utilizando combinação de Argissolo Vermelho-Amarelo eutrófico, esterco curtido e casca de arroz carbonizada e concluíram que a adição de esterco e casca de arroz interferiram negativamente, sendo o solo suficiente para suprir as necessidades da planta. Contudo, há carência de estudos comparando o desenvolvimento de mudas de baru em substratos com solos de diferentes texturas, o que dificulta a recomendação do tipo de solo para sua produção.

A luz é um dos componentes do meio, essencial e limitante ao desenvolvimento vegetativo, e as espécies vegetais possuem exigências específicas para seu crescimento (LARCHER, 2006). Assim, estudos sobre o efeito da intensidade luminosa no desenvolvimento de mudas são necessários para o cultivo do baru.

São escassas as informações quanto ao comportamento do baru sob sombreamento. É recomendado que as mudas sejam mantidas a pleno sol para evitar ataques de fungos. Por outro lado, Paiva Sobrinho et al. (2010) estudaram o desenvolvimento de mudas de baru em local sombreado ( $50 \%$ de sombra) e obtiveram plantas com altura e diâmetro 
de coleto adequado para o plantio.

O atual nível de conhecimentos justifica a avaliação do tipo de solo a ser utilizado no Cerrado para a produção de mudas de baru, especificamente quanto à textura, bem como os níveis de sombreamento adequados, tendo em vista a escassez de estudos nesta área e a importância destes fatores para a produção de mudas das frutíferas e nativas do Cerrado.

O objetivo neste trabalho foi avaliar o desenvolvimento de mudas de baru (Dipteryx alata Vog.) sob três níveis de luminosidade e quatro classes texturais de solo.

\section{MATERIAL E MÉTODOS}

O experimento foi desenvolvido no Centro de Pesquisa e Capacitação da AGRAER (537m de altitude; 20²5'12”'S; 5440’4”W), em Campo Grande-MS, no período de março a outubro de 2010. As mudas foram cultivadas em vasos com capacidade para oito litros.

Os tratamentos foram compostos de três níveis de sombreamento (0\%, 30\% e 50\% de sombra) e quatro classes texturais do solo (arenosa, média, argilosa e muito argilosa). O delineamento experimental foi de blocos ao acaso, em parcelas subdivididas, com medidas repetidas no tempo. Foram utilizadas três repetições e dez plantas por subparcela. Os níveis de sombreamento corresponderam aos tratamentos e às diferentes classes texturais do solo aos subtratamentos.

Os frutos de baru foram coletados em setembro de 2009, em Campo Grande-MS, em 20 árvores selecionadas pela boa conformação (produtivas e com ausência de pragas e/ou doenças). Foram selecionados frutos com largura de aproximadamente 30 $\mathrm{mm}$, que foram armazenados em sacos de papel por um período de maturação de 60 dias (CORREA et al., 2000). Foram extraídas cerca de 2.000 sementes com quebrador de baru (BAMBIL et al., 2011). Os solos de diferentes texturas para compor os substratos foram coletados em Campo Grande-MS, abaixo da camada de $20 \mathrm{~cm}$ de profundidade e submetidos à análise física e química (Tabela 1). Todos receberam calagem e adubação (Tabela 2) sem adição de adubo orgânico.

O Nitrogênio foi adicionado somente no início, não sendo utilizado em cobertura, uma vez que, no período de desenvolvimento das mudas, não se espera resposta à utilização deste nutriente. Os vasos foram colocados sob os telados com $30 \%$ e $50 \%$ de sombreamento e a pleno sol. Cada telado tinha dimensões de 2,2 m de altura, 2,0 m de largura e $3 \mathrm{~m}$ de comprimento, sendo dispostos à distância de $6 \mathrm{~m}$ entre si. Para os tratamentos sob sol,foram adotados retângulos com as mesmas dimensões dos telados. Foram semeadas em 27-03-2010, quatro sementes em cada vaso; após a germinação, foi realizado desbaste, mantendo-se uma planta por vaso. As mudas foram irrigadas de forma a manter a umidade do substrato próxima à capacidade de campo.

Em 20 de abril de 2010, 15 dias após a emergência (DAE), e a cada 15 dias, até 195 DAE (13 de outubro de 2010), foram tomadas medidas de altura de plantas, número de folhas e diâmetro do coleto de todas as plantas, utilizando-se de paquímetro digital. Aos $195 \mathrm{DAE}$, foram contadas as plantas que sobreviveram; foram colhidas as plantas cortando-as rente ao solo e separando-as em folhas e caules. A área foliar foi avaliada com integrador de área foliar tipo LICOR 3000, e as folhas e os caules foram secos em estufa de circulação forçada de ar, a $65^{\circ} \mathrm{C}$, até massa constante, para o cálculo de massa seca. Os vasos foram pesados e as amostras de solo foram retiradas para medir o teor de umidade; em seguida, os substratos foram lavados em água corrente sobre peneira de 1,58 mm de espessura de malha para a coleta das raízes de todas as plantas. As raízes foram secas em estufa de circulação forçada de ar, a $65^{\circ} \mathrm{C}$, até massa constante, para a avaliação da massa seca. Para a determinação da qualidade das mudas, foi avaliado também o índice de qualidade de Dickson (IQD), conforme Costa et al.(2011), aplicando-se a fórmula:

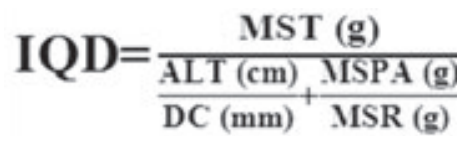

em que:

MST = Massa seca total(g) (MSPA+ MSR); ALT = Altura $(\mathrm{cm}) ; \mathrm{DC}=$ diâmetro do coleto $(\mathrm{mm})$; MSPA= Massa seca da parte aérea (g); MSR = massa seca de raízes (g).

Os dados foram submetidos à análise de variância e regressão. Às médias de altura de plantas, número de folhas e diâmetro do coleto foram ajustadas a equações de regressão em função dos dias após a emergência. Foi realizada análise de variância com os dados coletados, aos 195 DAE (final), sendo as médias comparadas pelo teste de Skott-Knott, ao nível de 5\% de probabilidade. Para a análise estatística, foi utilizado o aplicativo SAEG. 


\section{RESULTADOS E DISCUSSÃO}

A análise de variância indicou efeitos significativos $(\mathrm{P}<0,05)$ dos níveis de sombreamento, classes texturais do solo e DAE na altura de plantas e diâmetro do coleto. Para altura de planta, houve interação entre DAE e sombreamento, e DAE e classes texturais. No coleto, a interação foi entre o fator DAE e classes texturais do solo. No número de folhas, por sua vez, somente o fator DAE se mostrou significativo.

A equação de regressão ajustada para altura de plantas sob diferentes níveis de sombreamento (Figura 1a) permite verificar, nos primeiros 60 DAE, um maior crescimento em altura; no intervalo entre 60 a $150 \mathrm{DAE}$, o incremento do crescimento diminuiu, voltando a acelerar a partir desta fase. O período de menor crescimento correspondeu aos meses de junho, julho e agosto, nos quais ocorreram temperaturas médias mínimas de $16^{\circ} \mathrm{C}, 15^{\circ} \mathrm{C}$ e $16,4^{\circ} \mathrm{C}$, respectivamente; registrou-se, no mês de julho, temperatura mínima de $5^{\circ} \mathrm{C}$ (CEMTEC, 2010). Nota-se, também, que o crescimento de altura de plantas, nos diferentes níveis de sombreamento, estava mais próximo no início do desenvolvimento (Figura 1a). A partir de 120 DAE, é possível visualizar uma ampliação nas diferenças entre os níveis de sombreamento. Entre 165 DAE e 195 DAE (8 de setembro a 13 de outubro), o incremento médio da altura de plantas, em pleno sol, foi de aproximadamente $5 \mathrm{~cm}$, enquanto sob sombra foi de aproximadamente $8 \mathrm{~cm}$.

Pode-se deduzir que o crescimento maior em altura sob sombreamento, sem estiolamento, tenha ocorrido, em parte, devido à maior taxa de fotossíntese líquida. As mudas sob telado (sombra) foram protegidas, em certa medida, das condições climáticas estressantes, tais como alta radiação solar no início do desenvolvimento e, posteriormente, períodos de frio, além de ventos, cujas rajadas atingiram $69 \mathrm{~km} / \mathrm{h}$ e $72 \mathrm{~km} / \mathrm{h}$ nos meses de setembro e outubro (CEMTEC, 2010). Dessa forma, é razoável supor que as mudas, em pleno sol, foram afetadas pelos fatores climáticos, manifestando efeitos como a fotoinibição e redução de crescimento.

Considerando as diferentes classes texturais do solo, a equação de regressão de altura de plantas, durante os 195 DAE (Figura 1b), permite verificar que as classes texturais do solo que propiciaram maior crescimento em todo o ciclo foram de textura argilosa e muito argilosa, seguidas das texturas média e arenosa, o que está parcialmente de acordo com Sano et al. (2006), para quem o baru é mais bem adaptado a solos de textura arenoargilosa.
Em relação ao diâmetro do coleto, verificou-se, sob 50\% de sombreamento, valor superior aos demais níveis de sombreamento (Figura 2a). Resultado semelhante foi relatado por Marimon et al. (2008). Estes autores observaram maior valor de diâmetro de coleto para mudas de Brosimum rubenscens Taub. sob sombreamento (50\%), quando comparadas com mudas em pleno sol. No solo arenoso, o diâmetro do coleto foi significativamente inferior àquele das outras classes texturais do solo. Por meio da equação ajustada para diâmetro do coleto (Figura 2b), não foi possível observar, claramente, período de menor incremento de diâmetro no inverno. Aparentemente, o efeito das condições climáticas do inverno nesta seja menos intensa que na altura das plantas.

Na característica de número de folhas, verificou-se um incremento maior nos primeiros 30 DAE, diminuindo no intervalo dos 30 aos150 DAE e crescendo dos 150 até 195 DAE (Figura 3).

A evolução para as variáveis altura, diâmetro do coleto e número de folhas das mudas de baru, verificada neste experimento, concorda parcialmente com a verificação de Melo (1999). Este autor, avaliando o efeito de adição de nutrientes em mudas de baru,desenvolvidas em casa de vegetação, em substrato composto de solo argiloso por 210 dias, verificou que o incremento da altura foi maior nos primeiros 45 dias após a semeadura, o incremento do diâmetro do coleto foi contínuo, e o número de folhas, crescente, a partir dos 30 dias.

$\mathrm{Na}$ análise de variância realizada especificamente aos 195 DAE, ocorreram diferenças significativas $(\mathrm{P}<0,05)$ para os níveis de sombreamento e as classes texturais do solo na altura de plantas, número de folhas e área foliar. A percentagem de sobrevivência de plantas, IQD e massas secas de caule, folha e raízes foi influenciada apenas pelas classes texturais do solo. Houve interação significativa entre níveis de sombreamento e classes texturais do solo para a massa seca de raiz.

Sob sombreamento, as alturas das plantas e as áreas foliares foram maiores (Tabela 3). A área foliar maior sob sombra, certamente, ocorreu devido à necessidade de a planta ampliar a superfície fotossintetizante para maximizar a absorção luminosa. Efeito positivo do sombreamento, em comparação ao pleno sol, sob a altura de mudas foi verificado em Hymenaea courbaril L. (LIMA et al. , 2010); Schizolobium amazonicum Huber ex Ducke (ROSA et al., 2009); Brosimum rubescens Taub. (MARIMON et al., 2008).

O número de folhas, aos $195 \mathrm{DAE}$, foi maior a pleno sol do que à sombra (Tabela 3). Este fato pode ser devido às adaptações da planta à maior irradiação, que induz ao desenvolvimento de ramificações e, 
possivelmente, maior número de folhas. Observa-se que o aumento da ramificação não deve ser considerado um fato positivo, pois está relacionado com brotações que não são recomendáveis para uma muda de boa qualidade.

Aos 195 DAE, foram observados, no solo com textura argilosa, valores superiores para a maioria das características avaliadas, e, em sequência, os valores foram superiores no solo com textura muito argilosa, que foi inferior ao de textura argilosa somente na área foliar e na massa seca de folhas (Tabela 4). Destaca-se que o solo com textura argilosa, retirado de área com pastagem cultivada, aparentemente, recebeu correção e adubação em anos anteriores, pois mesmo nas camadas abaixo de $20 \mathrm{~cm}$ apresentou melhor nível de nutrientes e de saturação de bases que os outros solos utilizados, o que pode ter contribuído para os resultados (Tabela 1 ).

Em mudas desenvolvidas em solo com textura arenosa, a percentagem de sobrevivência foi significativamente inferior aos demais (Tabela 4). Foi possível observar, no solo com textura arenosa, uma temperatura mais elevada durante o período de germinação e desenvolvimento inicial das plântulas; este fato, aparentemente, gerou danos nas mudas e favoreceu o aparecimento de fungos que causaram a mortalidade de plântulas. Nesta classe textural de solo, os valores de diâmetro do coleto, massa seca de folhas e de caule, e o IQD foram inferiores em comparação às demais classes texturais estudadas. Tal resultado corrobora os de Binotto et al. (2010). Os autores observaram que as variáveis com maior relação com o IQD são as fitomassas secas, seguidas do diâmetro do coleto.

Na massa seca de raiz, observou-se que, dentro dos níveis de sombreamento, os resultados nas classes texturais do solo foram diferenciados (Tabela 5). O solo de textura muito argilosa proporcionou mais produção de raízes sob 50\% de sombreamento, enquanto os solos de textura argilosa e média proporcionaram menor produção de raízes com o aumento do nível de sombreamento e, no solo de textura arenosa, não ocorreu diferença significativa entre os níveis de sombreamento. Este comportamento diferenciado é responsável pela interação observada e de difícil elucidação.

Em todos os níveis de sombra, verificou-se, no solo com textura arenosa, menor quantidade de raízes em comparação aos demais (Tabela 5). A menor produção de raízes em solos de textura arenosa, em relação a solos de classes mais argilosas, tem sido verificada em pastagens cultivadas (VOLPE et al., 2008). É possível considerar que a ocorrência de maior quantidade de microporos nos solos com textura mais argilosa aumente a necessidade de a planta emitir mais raízes para melhor aproveitamento de água e nutrientes. No caso de nutrientes, sabe-se que a disponibilidade de $\mathrm{P}$ em solos de textura mais arenosa é maior em relação aos solos mais argilosos intemperizados, que apresentam alta capacidade de adsorção deste nutriente e induz a planta a emitir mais raízes para ampliar sua superfície de absorção.

Durante a avaliação das raízes, não foi verificada a presença de nódulos de bactérias fixadoras de Nitrogênio. 

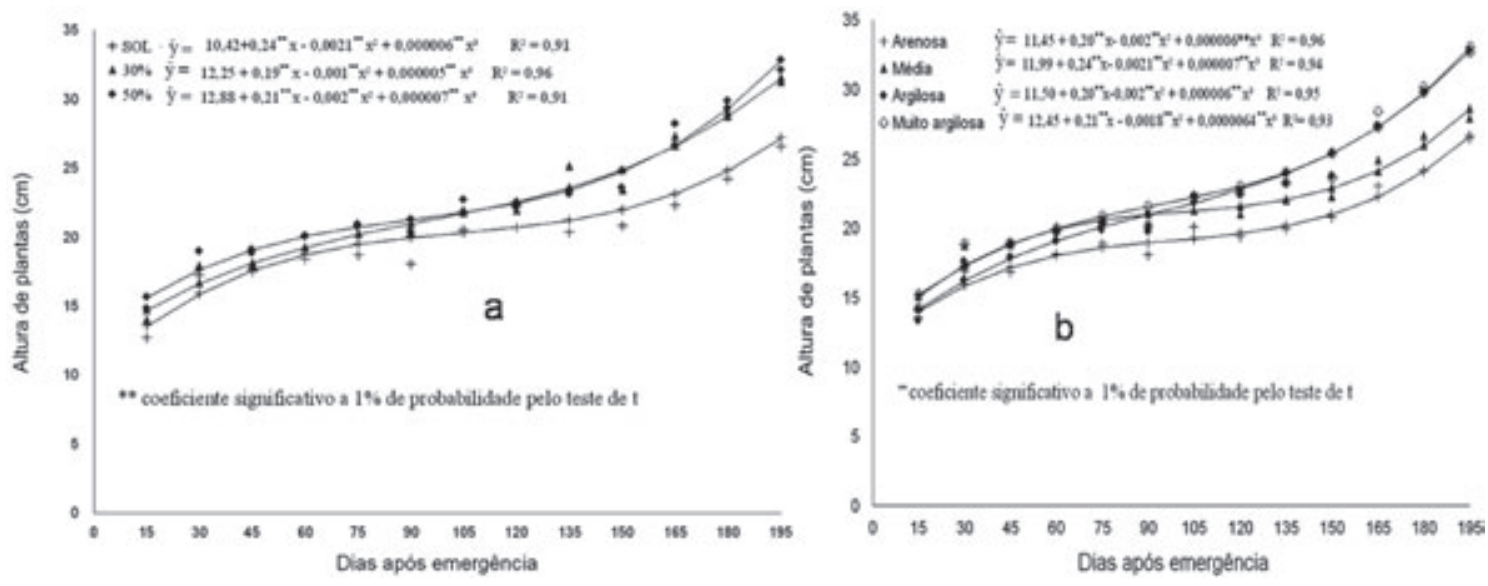

FIGURA1 - Altura de plantas de baru sob diferentes níveis de sombreamento (a) e diferentes substratos (b), durante o período de desenvolvimento de mudas. Campo Grande - MS, 2010.
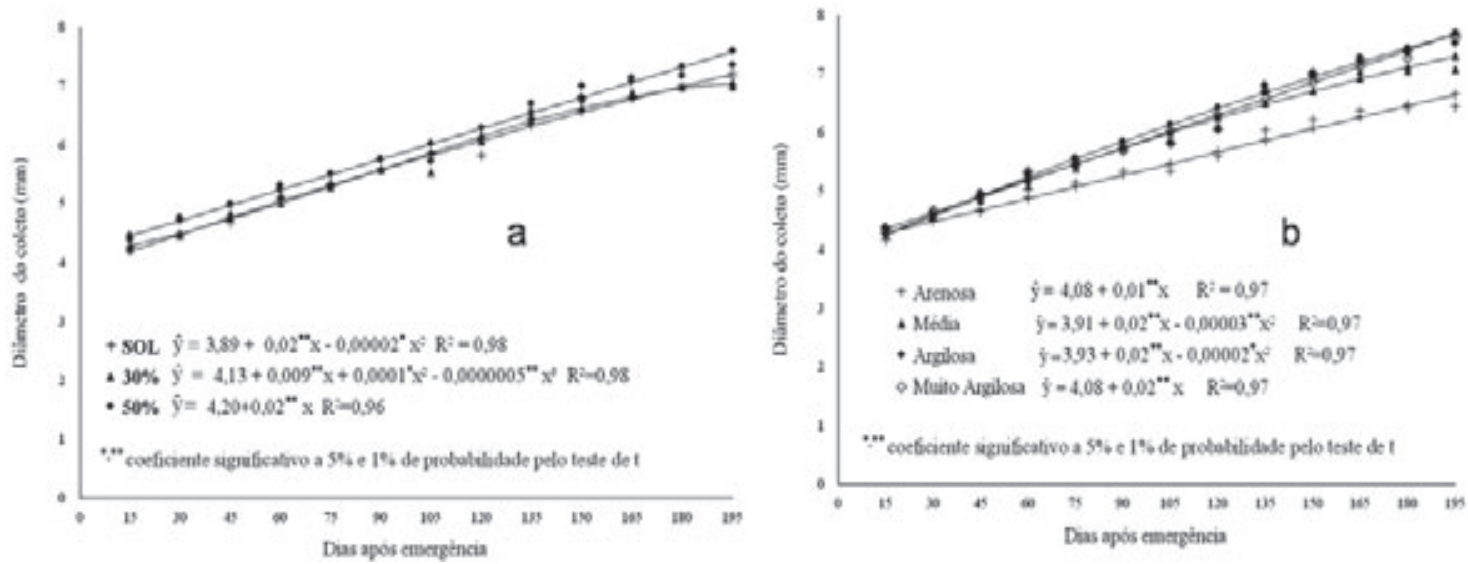

FIGURA 2 - Diâmetro do coleto de plantas de baru sob diferentes níveis de sombreamento (a) e diferentes substratos (b), durante o período de desenvolvimento de mudas. Campo Grande - MS, 2010.

TABELA 1 - Textura e composição química dos solos utilizados como substrato. Campo Grande - MS, 2010

\begin{tabular}{|c|c|c|c|c|c|c|c|c|c|c|c|c|}
\hline \multirow{2}{*}{$\begin{array}{l}\text { Classes } \\
\text { texturais }\end{array}$} & $\begin{array}{c}\text { Teor } \\
\text { de argila }\end{array}$ & $\mathrm{PH} \mathrm{H}_{2} \mathrm{O}$ & M.O. & $\mathrm{P}$ & K & $\mathrm{Ca}$ & $\mathrm{Mg}$ & $\mathrm{Ca}+\mathrm{Mg}$ & $\mathrm{H}+\mathrm{Al}$ & SB & $\mathrm{T}$ & \multirow{2}{*}{$\begin{array}{c}\mathrm{V} \\
\%\end{array}$} \\
\hline & $\mathrm{g} \mathrm{kg}^{-1}$ & & $\mathrm{~g} \mathrm{dm}^{-3}$ & $\mathrm{mg} \mathrm{dm}^{-3}$ & ------ & ----- & ------ & $\mathrm{cmol} \mathrm{dm}$ & $n^{-3}--$ & - & ---- & \\
\hline Arenosa & 10 & 5,05 & 9,47 & 4,52 & 0,02 & -- & -- & 0,45 & 2,13 & 0,47 & 2,60 & 18,90 \\
\hline Média & 26 & 4,81 & 16,2 & 2,58 & 0,07 & -- & -- & 0,50 & 4,39 & 0,57 & 4,96 & 11,49 \\
\hline Argilosa & 50 & 5,28 & 31,74 & 2,07 & 0,43 & 2,05 & 1,1 & 3,15 & 5,73 & 3,58 & 9,31 & 38,45 \\
\hline $\begin{array}{c}\text { Muito } \\
\text { argilosa }\end{array}$ & 61 & 5,1 & 10,46 & 0,71 & 0,08 & 0,75 & 0,4 & 1,15 & 4,02 & 1,23 & 5,25 & 23,43 \\
\hline
\end{tabular}




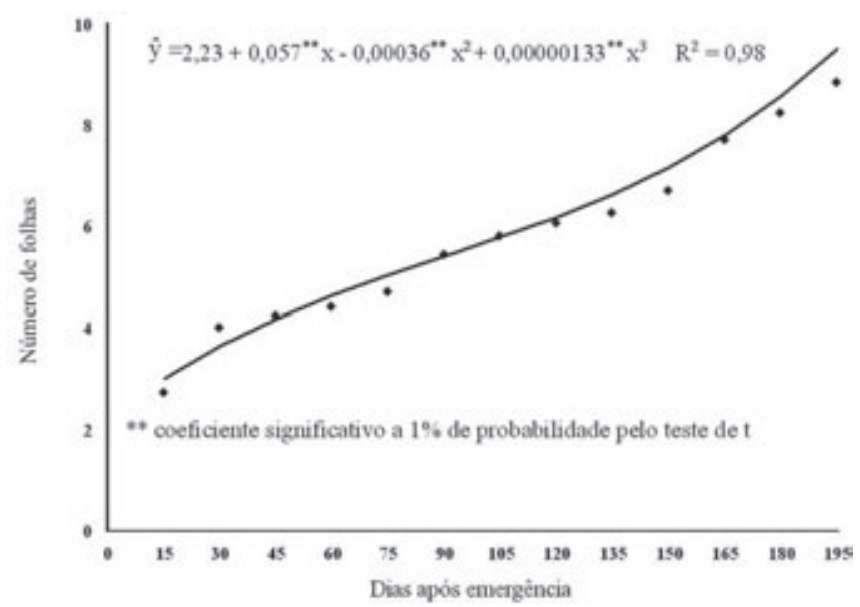

FIGURA 3 - Número de folhas de plantas de baru durante o período de desenvolvimento de mudas. Campo Grande - MS, 2010.

TABELA 2 - Calagem e adubação em substratos para mudas de baru.Campo Grande - MS , 2010.

\begin{tabular}{ccc}
\hline Nutriente & Quantidade & Fonte \\
\hline Calcário & $1 \mathrm{~g} \mathrm{~L}^{-1}$ & \\
Nitrogênio & $40 \mathrm{mg} \mathrm{L}^{-1}$ & Sulfato de amônio \\
Fósforo & $160 \mathrm{mg} \mathrm{L}^{-1}$ & Superfosfato triplo \\
Potássio & $24 \mathrm{mg} \mathrm{g} \mathrm{L}^{-1}$ & Cloreto de potássio \\
Boro & $1,08 \mathrm{mg} \mathrm{L}^{-1}$ & FTE BR-12 \\
Cobre & $0,48 \mathrm{mg} \mathrm{L}^{-1}$ & FTE BR-12 \\
Manganês & $1,68 \mathrm{mg} \mathrm{L}^{-1}$ & FTE BR-12 \\
Molibidênio & $0,06 \mathrm{mg} \mathrm{L}^{-1}$ & FTE BR-12 \\
Zincon & $5,40 \mathrm{mg} \mathrm{L}^{-1}$ & FTE BR-12 \\
\hline
\end{tabular}

${ }^{1}$ Ca: 7,10\%; S: 5,7\%; B: 1,8\%; Cu: 0,80\%; Mn: 2,8\%; Mo: 0,10\%; Zn: $9 \%$

TABELA 3 - Área foliar (AF), altura e número de folhas (NF) de mudas de baru, submetidas a três níveis de sombreamento, aos 195 dias após a emergência. Campo Grande - MS, 2010

\begin{tabular}{cccc}
\hline Nível de sombreamento $(\%)$ & AF $\left(\mathrm{cm}^{2}\right)$ & ALTURA $(\mathrm{cm})$ & NF \\
\hline 0 & $436,89 \mathrm{~b}$ & $26,53 \mathrm{~b}$ & $9,64 \mathrm{a}$ \\
30 & $580,49 \mathrm{a}$ & $31,21 \mathrm{a}$ & $9,23 \mathrm{~b}$ \\
50 & $639,24 \mathrm{a}$ & $32,09 \mathrm{a}$ & $8,97 \mathrm{~b}$ \\
\hline Médias & 552,21 & 29,94 & 9,28 \\
\hline CV $(\%)$ & 18,99 & 4,72 & 3,60 \\
\hline
\end{tabular}

Médias seguidas pelas mesmas letras, nas colunas, não diferem, pelo teste Scott-Knott, a 5\% de probabilidade.

TABELA 4 - Altura de plantas, diâmetro do coleto (DC), percentagem de plantas vivas (PV), número de folhas (NF), área foliar (AF), índice de qualidade de Dickson (IQD), massa seca de folha (MSF) e massa seca de caule (MSC) por planta de mudas de baru, desenvolvidas em substratos com diferentes classes texturais de solo, aos 195 dias após a emergência. Campo Grande-MS, 2010.

\begin{tabular}{ccccccccc}
\hline $\begin{array}{c}\text { Classes } \\
\text { texturais }\end{array}$ & $\begin{array}{c}\text { Altura } \\
\mathrm{cm}\end{array}$ & $\begin{array}{c}\mathrm{DC} \\
\mathrm{mm}\end{array}$ & $\begin{array}{c}\mathrm{PV} \\
\%\end{array}$ & NF & AF cm ${ }^{2}$ & IQD & MSF & $\begin{array}{c}\text { MSC } \\
---- \text { g planta }^{-1}----\end{array}$ \\
\hline Arenosa & $26,43 \mathrm{~b}$ & $6,43 \mathrm{c}$ & $85,56 \mathrm{~b}$ & $8,52 \mathrm{~b}$ & $427,60 \mathrm{~b}$ & $2,33 \mathrm{c}$ & $4,29 \mathrm{~d}$ & $1,57 \mathrm{c}$ \\
Média & $27,91 \mathrm{~b}$ & $7,06 \mathrm{~b}$ & $95,56 \mathrm{a}$ & $9,08 \mathrm{a}$ & $500,70 \mathrm{~b}$ & $3,35 \mathrm{a}$ & $4,97 \mathrm{c}$ & $2,16 \mathrm{~b}$ \\
Argilosa & $32,78 \mathrm{a}$ & $7,51 \mathrm{a}$ & $94,44 \mathrm{a}$ & $9,65 \mathrm{a}$ & $778,24 \mathrm{a}$ & $3,60 \mathrm{a}$ & $7,28 \mathrm{a}$ & $2,64 \mathrm{a}$ \\
Muito argilosa & $32,67 \mathrm{a}$ & $7,61 \mathrm{a}$ & $97,78 \mathrm{a}$ & $9,89 \mathrm{a}$ & $502,29 \mathrm{~b}$ & $3,02 \mathrm{~b}$ & $5,84 \mathrm{~b}$ & $2,44 \mathrm{a}$ \\
\hline Médias & 29,95 & 7,15 & 93,34 & 9,28 & 552,21 & 3,075 & 5,59 & 2,20 \\
\hline CV $(\%)$ & 7,67 & 6,88 & 7,58 & 9,30 & 21,34 & 11,68 & 10,24 & 14,53 \\
\hline
\end{tabular}

Médias seguidas pelas mesmas letras, nas colunas, não diferem, pelo teste Scott-Knott, a 5\% de probabilidade. 
TABELA 5 - Massa seca de raiz (g de raiz por kg de solo) de mudas de baru, submetidas a diferentes níveis de sombreamento e quatro classes texturais de solo como substrato, aos 195 dias após a emergência. Campo Grande - MS, 2010.

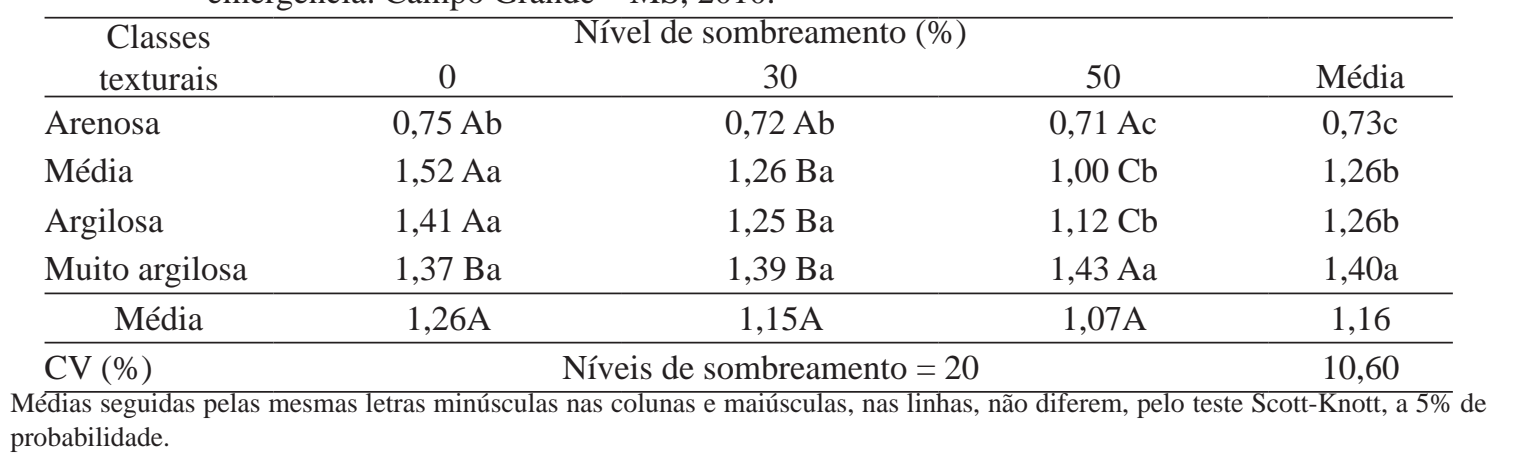

\section{CONCLUSÃO}

1-As mudas de baru apresentam melhor desenvolvimento em condições de sombreamento (30\% ou $50 \%$ de sombra) do que em pleno sol e em solo de textura argilosa e muito argilosa. O menor IDQ é verificado em mudas em solo sob textura arenosa.

2-A altura de plantas e o diâmetro de coleto das mudas de baru atingem valores médios suficientes para serem consideradas de boa qualidade quando produzidas entre o outono e o início da primavera.

\section{AGRADECIMENTOS}

À Fundação de Apoio ao Desenvolvimento do Ensino, Ciência e Tecnologia do Estado de Mato Grosso do Sul - FUNDECT - MS, pela bolsa concedida à primeira autora.

\section{REFERÊNCIAS}

BAMBIL, A.L.; DRUMOND, D.; VOLPE, E.; OLIVEIRA, I.; FEHQUER, T. J.; ROCHA, C. da; SILVEIRA, J. C. da. Baru: uma experiência de desenvolvimento tecnológico participativo em assentamentos. Campo Grande: AGRAER/ CNPq, 2011. 28 p.

BINOTTO, F.; LÚCIO, D. C. A.; LOPES, S. J.; Betwen growth variables and the Dickson quality índex in Forest seedling. Cerne, Lavras, v. 16, n. 4,p.457-464,2010.

CEMTEC/AGRAER/INMET. Dados meterológicos de Campo Grande-MS do ano de 2010. Campo Grande: Centro de Monitoramento de Tempo, Clima e dos Recursos Hídricos de Mato Grosso do Sul. Disponível em: $<$ http//www.agraer.ms.gov.br/cemtec $>$. Acesso em: 10 mar. 2011.
COELHO, M. F. B.; SOUZA, R. L. C. ; ALKBUQUERQUE, M. C. F.; WEBER, O. S.; NOGUEIRABORGES, H. B.; Qualidade de mudas de nó-de-cachorro (Heteropteris aphrodisiaca O. Mach.) em diferentes substratos. Revista Brasiliera de Plantas Medicinais, Botucatu, v. 10, n. 3, p. 82-90, 2008.

CORRÊA, G.de C.; ROCHA, M. R. da; NAVES, R. V. Germinação de sementes e emergência de plântulas de baru (Dipteryx alata Vog.) Cerrados do Estado de Goiás. Pesquisa Agropecuária Tropical, Goiânia, v.30, n.2, p.17-23, 2000

COSTA, E. ; LEAL, P. A. M.; REGO, N. H. ; BENATTI, J. Desenvolvimento inicial de mudas de jatobazeiro do cerrado em Aquidauana - MS. Revista Brasileira de Fruticultura, Jaboticabal, v. 33, n. 1, p. 215-226, 2011.

FERNANDES, D. C.; FREITAS, J. B.; CZEDER, L. P.; NAVES, M. M. V. Nutritional composition and protein value of the baru (Dipteryx alata Vog.) almond from the Brazilian Savanna. Journal of the Science of Food and Agriculture, New York, v. 90, n. 10, p. 1650-1655, 2010.

GODOY, T. G.; ROSADO, S. C. da S. Estimates of genetic gains for growth traits in Young plants of Eucalyptus urophylla S. T. Blake. Cerne, Lavras, v. 17, n. 2, p. 189-193, 2011.

LARCHER, W. Ecofisiologia vegetal. São Carlos: RIMA, 2006. 550 p.

LIMA. A. L. da S.; ZANELLA, F.; CASTRO, LEY, D. M. Crescimento de Hymenae courbaril L. var. stilbocarpa (Hayne) Lee et Lang. e Enterolobium contortisiquum (Vll.) Morang (Leguminosae) sob diferentes níveis de sombreamento. Acta Amazonica, Manaus, v. 40, n. 1, p. 43-48, 2010. 
MARANA, J. P.; MIGLIORANZA, E.; FONSECA, E. de P.; KAINUMA, R. H. índices de qualidade e crescimento de mudas de café produzidas em tubetes. Ciência Rural, Santa Maria, v. 38, n. 1, p. 39-45, 2008.

MARIMON, S. B.; FELFINI, J. M. ; MARINON JÚNIOR, B.; FRANCO, A. C.; FAGG, C. W. Desenvolvimento inicial e partição de biomassa de Brosimum runbescens Taub. (Moraceae) sob diferentes níveis de sombreamento. Acta Botanica Brasílica, Feira de Santana, v. 22, n. 4, p. 941-953, 2008.

MELO, J. T. de. Resposta de mudas de espécies arbóreas do cerrado à nutrientes em Latossolo vermelho escuro. 1999. $118 \mathrm{f}$. Tese (Doutorado em Ecologia) - Universidade Federal Brasília, Brasilia, 1999.

MELO, R. R.; CUNHA, M. do C. L. ; STANGERLIN, D., M. Crescimento inicial de mudas de Enterolobium contortisiliquun (Vell.) Morong. sob diferentes níveis de luminosidade. Revista Brasileira de Ciências Agrárias, Recife, v. 3, n. 2, 2008.

OLIVEIRA, M. I. B.; SIGRIST, M. R. Fenologia reprodutiva, polinização e reprodução de Dipteryx alata Vog. (Leguminosae- Papilionoidae) em Mato Grosso do Sul. Revista Brasileira de Botânica, São Paulo, v.31, n. 2, p. 195-207, 2008.

PACHECO, A. R. Adubação de mudas de baru (Dipteryx alata Vog.) em viveiro. .2008. 83f. Tese (Doutorado em Agronomia - Produção vegetal)- Universidade Federal de Goiás, Goiânia, 2008.

PAIVA SOBRINHO, S.; LUZ, P. B. da; SILVEIRA, L. S. T.; RAMOS, D.T.; NEVES, L. G.; BARELLI, M. A. A. Substratos na produção de mudas de três espécies arbóreas do cerrado. Revista Brasileira de Ciências Agrárias, Recife, v.5, n. 2, p. 238-243, 2010.
ROSA, A. C. G.; GOMES JÚNIOR, J. A.; GIACULI, E. A. F.; OLIVEIRA, C. M. de; PAULA, L. V. de. Efeito de diferentes substratos na produção de mudas de baru (Dipteryx alata). In: REUNIÃO ANUAL SBPC, 2006, Florianópolis. Anais... Florianópolis: UFSC, 2006. Disponível em: <http://www.sbpcnet. org.br>. Acesso em: 10 mar. 2011.

ROSA, L. dos S.; VIEIRA, T. A.; SANTOS, D. S.; SILVA, L. C. B. da. Emergência, crescimento e padrão de qualidade de mudas de Schizolobium amazonicum Huber ex Ducke sob diferentes níveis de sombreamento e profundidade de semeadura. Revista de Ciências Agrária, Belém, n. 52, p. 87-98, 2009

SANO, S. M., FONSECA, E. L. da F. Taxa de sobrevivência e frutificação de espécies nativas do Cerrado. Planaltina: EMBRAPA-CPAC, 2003. 20p. (Boletim de Pesquisa e Desenvolvimento, 83).

SANO, S. M.; BRITO, M. A. de; RIBEIRO, J. F. Baru In.: VIEIRA, R. F.; COSTA, T. da S.; SILVA, D. B. da; FERRREIRA, F. R. ; SANO, S. M. (Ed.). Frutas nativas da região Centro - Oeste do Brasil. Brasília: Embrapa Recursos Genéticos, 2006. p. 76-99.

SOUSA, A. G. de O.; FERNANDES, D. C.; ALVES, A. M.; FREITAS, J. B. de.; NAVES, M. M. V. Nutritional quality and protein value of exotic almonds and nut from the Brazilian Savanna compared to peanut. Food Research International, Barking, v. 44, n.7, p. $2319-2325,2011$

VOLPE, E.; MARCHETTI, M. E.; MACEDO, M. C. M.; ROSA JUNIOR, E. J. Renovação de pastagem degradada com calagem, adubação e leguminosa consorciada em Neossolo Quartzarênico. Acta Scientiarum Agronomy, Maringá, v. 30, n.1, p. 131-138, 2008.

ZAIDAN,L. B. P.; CARREIRA, R. Seed germination in Cerrado species. Brazilian Journal Plant Physiology, Piracicaba, v.20, n. 3, p. 167-181, 2008. 